\title{
Addition of dexmedetomidine and neostigmine to $1.5 \%$ lidocaine and triamcinolone for epidural block to reduce the duration of analgesia in patients suffering from chronic low back pain
}

\author{
Shima Zargar ${ }^{1}$, Ali Nazemi Rafie², Alireza Sosanabadi ${ }^{1}$, Alireza Kamali ${ }^{1}$ \\ 1. Department of Anesthesiology and Critical Care, Arak University of Medical Sciences, Arak, Iran \\ 2. Department of Neurosurgery, Arak University of Medical Sciences, Arak, Iran \\ Corresponding Author: \\ Alireza Kamali \\ Department of Anesthesiology and Critical Care, \\ Arak University of Medical Sciences, Arak, Iran \\ Tel. 00989181622810 Email: alikamaliir@yahoo.com \\ Received: May 10th, 2019 - Accepted: August 1st, 2019
}

\begin{abstract}
Lower back pain is one of the leading causes of disability in the world. The aim of this study was to evaluate the effect of supplementation of dexmedetomidine and neostigmine with lidocaine $1.5 \%$ and triamcinolone for epidural block in increasing the duration of analgesia among patients suffering from chronic low back pain. In this double-blind, randomized clinical trial, 33 patients with chronic low back pain were included in three groups of 11 patients for epidural blockage. Triamcinolone $(40 \mathrm{mg} / \mathrm{ml})$ was added to lidocaine $1.5 \%$ solution ( $2 \mathrm{cc} /$ segment) for all three groups. In group $\mathrm{N}$, neostigmine was used at a dose of $1 \mathrm{mg}(\mathrm{mg})$, followed by group $\mathrm{D}$ (dexmedetomidine $35 \mu \mathrm{g}[0.5 \mu \mathrm{g} / \mathrm{kg}$ ]), and grou [ND (neostigmine $0.5 \mathrm{mg}$, and $35 \mu \mathrm{g}$ dexmedetomidine, all of which were added to the triamcinolone and lidocaine solution in each group. Medications were injected into the epidural space using an interlaminar approach. Subsequently, scores of pain and duration of analgesia were recorded in questionnaires and analysed using SPSS version 23. One month after the injections, pain scores recorded in the $N$ group were $7.6 \pm 1.4$, followed by $5.88 \pm 1.2$ in group $D$ and $5.42 \pm 1.1$ in group ND. Therefore, the pain scores were significantly higher in the neostigmine group than the other two groups $(p=0.02)$, but no significant difference was found between the two groups that received dexmedetomidine and a combination of dexmedetomidine + neostigmine. Three months after the injections, there was a significant difference in pain scores between the two groups $(P=0.01)$. Both neostigmine and dexmedetomidine were capable of reducing the pain of patients with chronic low back pain after epidural block. However, neostigmine's impact is lower compared to dexmedetomidine. The combination of the two drugs also reduced the pain scores of the patients after the intervention.
\end{abstract}

Keywords: Lower back pain, Epidural injection, Neostigmine, dexmedetomidine hydrochloride

\section{Introduction}

Over the past two decades, extensive epidemiological studies have been carried out on low back pain and indicate high prevalence and high direct and indirect costs in areas such as medical, legal, employment (absenteeism), products, and inadequate quality of life [1, 2]. More than $80 \%$ of the population will experience at least one episode of low back pain during their life [2,3].

According to estimates, approximately $1 \%$ to $2 \%$ of the active population in the United States suffers from severe disability due to back pain, and $12 \%$ to $15 \%$ of annual visits of patients in American healthcare centers have been attributed to back pain. $12 \%$ to $15 \%$ of annual visits to patients in American health care centers due to low back pain. In Iran, back pain is one of the issues that is common in the society, with high prevalence among high school students (17\%), nurses (62\%) and pregnant women (84\%) [1]. Most patients suffering from acute low back pain usually experience symptoms of healing thanks to preservative or spontaneous therapies within 4 to 6 weeks. In the event of symptoms persisting for more than three months, we talk about chronic low back pain $[3,4]$. The main goal in the treatment of chronic low back pain is to relieve pain temporarily so that the patient can participate in therapeutic exercises and a coherent rehab program.

In this way, the strength and mechanics of the patient's body improve, physical stress will be minimized, and pain will be resolved for a longer period [4] Among the less invasive methods, epidural injections are one of the most commonly used measures to reduce low back pain and lower limb pain, leading to improvement of the quality of life [5]. An epidural injection is especially beneficial 
in patients whose chronic pain does not respond to conservative and physiotherapy treatments [6].

Despite extensive research in this area, there is still controversy over the number of epidural infusions and their maximum frequency, and the administration route of the epidural injection (transforaminal, interlaminar and caudal). In addition, the researchers still failed to reach agreement on the ideal volume of consumed drugs, injections or non-injections of corticosteroids, drug alternatives as to the main epidural anesthetic drug, adjuvant drugs and the effectiveness of these methods in reducing patient's pain [5-12]. Different adjuvants have been used in combination with local anesthetics to improve analgesia and to reduce complications, but none have been accepted [13]. Meanwhile, dexmedetomidine and neostigmine are effective adjuvants used in the lumbar epidural blocks [14, 15]. Neostigmine is an acetylcholinesterase inhibitor, and its analgesic effects are owed to increased acetylcholine concentrations in the posterior spinal cord and meninges. According to some studies, the use of neostigmine in combination with local anesthetics and opioids has a synergistic and postoperative effect, which increases the duration of analgesia and decreases the VAS (visual analogue scale) score [16].

Other adjuvant drugs include dexmedetomidine, which is a highly sensitive and highly selective $\alpha-2$ adrenergic receptor agonist with a tendency of more than 8-fold in comparison with clonidine, thus reducing undesired side effects of alpha-1 receptors [12, 17]. Various studies have shown that dexmedetomidine is capable of increasing the sensory block, motor block and also the duration of analgesia [17]. According to these interpretations, this study was aimed to compare the effect of two drugs (neostigmine and dexmedetomidine) as adjuvant drugs along with lidocaine and corticosteroids in increasing the duration of analgesia in patients suffering from chronic low back pain for improving the quality of life among these patients.

\section{Materials and Methods}

This study was a double-blind, randomized clinical trial on all patients with chronic low back pain who were considered an epidural block candidate at the Amiralmomenin Hospital and Vali Asr Hospital in Arak, Iran.

\section{Inclusion criteria}

1. All patients with chronic low back pain who were candidates for the lumbar epidural block. 2. All patients with the intent to participate in the study. 3. Patients aged 30-70 years 4. Patients with physical status ASA I or II. 5 . Absence of vitamin $D$ deficiency.

\section{Exclusion criteria}

1. Patients outside the age range of $30-70$ years 2 . Patients who were not candidates for an epidural block. 3. Patients with hypersensitivity to lidocaine neostigmine and dexmedetomidine. 4. Patients with physical status ASA greater than II (III, IV). 5. Patients with failed epidural blocks. 6 . Female patients who are pregnant or lactating. 7. Patients with a history of fracture. 8. Patients who are suffering from uncontrolled psychological disorders.

In this study, all patients with chronic low back pain (back pain for more than 6 weeks), candidates for epidural block with physical status ASA I or II, who have never had an allergic reaction to local anesthetics and epidural anesthesia were randomly divided into three groups: N (Neostigmine), D (Dexmedetomidine), and ND (Neostigmine and Dexmedetomidine). Patients who met the inclusion criteria and provided written informed consent were included in the study. At first, the Ringer solution of $5 \mathrm{cc} / \mathrm{kg}$ was injected 10 to 15 minutes before the epidural block for adequate hydration for each patient of the three groups. Afterward, the patients were placed in a sitting position, and the subjects received epidural blocks at the L4-L5 or L5-S1 level using the interlaminar approach using a 19- or 20-gauge epidural catheter. After entering the epidural space and confirming the correctness of needle placement, the drug combination was injected. In all three groups, $2 \mathrm{cc} /$ segment of triamcinolone $(40 \mathrm{mg} / \mathrm{ml})$ was added to the lidocaine $1.5 \%$ solution, followed by injection.

In group N, neostigmine was used at a dose of 1 $\mathrm{mg}(\mathrm{mg})$, followed by group $\mathrm{D}$ (dexmedetomidine 35 $\mu \mathrm{g}[0.5 \mu \mathrm{g} / \mathrm{kg}]$ ) and group ND (neostigmine $0.5 \mathrm{mg}$, and $35 \mu \mathrm{g}$ dexmedetomidine, all of which were added to the triamcinolone and lidocaine solution in each group. The volume of the injectable solution was mixed with distilled water up to $20 \mathrm{cc}$ for each of the three groups.

During epidural blocking, SPO2 (pulse oxygen saturation), PR (pulse rate) and NIBP (non-invasive blood pressure) were monitored. Ultimately, after performing the procedure and ensuring that the hemodynamic status of the patient was stable, they were transferred to the recovery room. Complete monitoring (including SPO2, PR, NIBP,) was continued even after the patients were transferred to the recovery room.

\section{Double-blind procedure}

This double-blind study included patients who provided written informed consent, the injectable solution composition being unknown. Furthermore, the healthcare professional responsible for completing the questionnaires and recording the pain and disability scores, was not aware of the patients in the studied groups and did not know about the epidural block, only completing questionnaires 
based on the numbers assigned in the operating room by an anesthesiologist responsible for the study (who performed the procedure).

A total of 33 patients with chronic low back pain who met the inclusion criteria were randomly assigned to three groups (N, D, and ND) using a randomized table. Therefore, 11 patients were assigned to each group.

\section{Data collection}

The pain score and duration of analgesia were evaluated based on the visual analogue scale (VAS) in the recovery room, one month and three months after the procedure. Improvement of performance was also evaluated based on the score of disability (ODI - Oswestry Disability Index) before and one month after the intervention. The duration of analgesia was recorded on the basis of a painkiller request (in terms of days); therefore, all patients were requested to return to the clinic or address to a pain management clinic if the pain would return. The exact duration of analgesia was recorded in the questionnaires to track the patients' pain. Also, other patient information, including demographic data, hemodynamic status (SPO2, PR, NIBP) during the procedure and recovery, as well as the mean time needed for movement onset were recorded by questionnaires.

\section{Sample size and sampling method}

According to the type of study (randomized clinical trial), 33 patients who met the inclusion criteria and provided written informed consent, were randomly assigned to three equal groups: N (neostigmine), D (dexmedetomidine) and DN (dexmedetomidine and neostigmine).

$$
\begin{aligned}
& n=\frac{2\left(z_{1-\frac{a}{2}}+z_{1-b}\right)^{2} \times\left(d_{1}+d_{2}\right)^{2}}{\left(m-m_{2}\right)^{2}} \\
& =\frac{18.4 \times(4.6+4.2)^{2}}{(20.9-36.9)^{2}} \\
& =\frac{18.4 \times 77.4}{256} \\
& \Rightarrow n=11 \stackrel{\times 3}{\Rightarrow} 33 \text { subjects } \\
& z_{1-\frac{a}{2}}=1.96 \quad d_{1}=4.6 \quad m=36.9 \\
& z_{1-b}=2.33 \quad d_{2}=4.2 \quad m_{2}=20.9
\end{aligned}
$$

\section{Data analysis}

In this study, SPSS 19 software was used to analyze questionnaires data. Statistical analysis was performed using T-test and ANOVA. Finally, the results were shown in Tables and graphs.

\section{Ethical considerations}

In this study, the names and characteristics of the subjects were confidential and costs were not imposed on the patient's family and hospital. In addition, completion of the form and the patients were satisfied after receiving training providing written consent. At all stages of the research, such as drafting the proposal, collecting samples and analyzing data, the researchers were required to respect the ethical provisions issued by the Ministry of Health and the Helsinki Declaration. This research was approved by the Ethics Committee of the Arak Medical University Research Council (IR.ARAKMU.REC.1395.256).

\section{Results}

A total of 11 patients were enrolled in each group; the mean age and distribution of the sexual abnormalities of these patients are listed in Table 1. According to Table 1, there was no significant difference between the three groups in terms of mean age since the average age of the patients was similar $(P=0.3)$. Regarding the distribution of sexual frequency, there was no significant difference either (the frequency of male subjects was similar in the three groups - $55 \% ; P=0.4$ ).

Based on Table 2, no significant difference was found between the three groups regarding the duration of chronic low back pain before the intervention; the duration of back pain was found to be similar in all three groups, which was almost equal to 1.7 years $(p=0.6)$.

As indicated in Table 3, no significant difference was observed between the three groups in terms of recovery pain scores and almost every score was revealed to be less than 0.5. However, pain scores were different in the three groups one month after the injection, the pain scores in the neostigmine

\begin{tabular}{|c|c|c|c|c|}
\hline Mean age/Group & Neostigmine group & Dexmedetomidine group & Combined group & P-value \\
\hline Age average & $41 / 7+/-2 / 3$ & $42 / 4-/+1 / 9$ & $43 / 3-/+2 / 7$ & $\begin{array}{c}P=0.3 \\
\text { No significance }\end{array}$ \\
\hline \multirow[t]{2}{*}{ Frequency distribution } & $57.1 \%$ & $55.4 \%$ & $56.6 \%$ & \multirow{2}{*}{$\begin{array}{c}P=0.4 \\
\text { No significance }\end{array}$} \\
\hline & Female & $44.6 \%$ & $43.4 \%$ & \\
\hline
\end{tabular}
group being significantly higher than the other two groups $(p=$ 0.02 ), but no significant difference was observed between the neostigmine group and dexmedetomidine group compared to the combined group (dexmedetomidine+ neostigmine).

Table 1: Comparison of mean age and sex distribution of patients with chronic low back pain of the three groups 
Nevertheless, pain scores were significantly different at three months after the injection; the pain scores in the neostigmine group were higher than the other two groups $(p=0.01)$, but no significant difference was revealed between the dexmedetomidine and combined group (dexmedetomidine + neostigmine).

As Table 4 suggests, the duration of analgesia in the neostigmine group was significantly lower as compared to the other two groups $(P=0.03)$, while there was no significant difference between the dexmedetomidine and combined group. In other words, the effect of dexmedetomidine was far more pronounced than that of neostigmine, either alone or in combination.

According to Table 5, no significant difference between was observed between the three groups regarding movement after the intervention, and the same result was observed in all three groups ( 2.5 hours; $p=0.06$ ).

Our findings showed no significant difference between the three groups in terms of ODI scoring before the intervention; almost all ODI scores were the same in all three groups (45\%; $p=0.06)$. However, the ODI score was significantly higher in the neostigmine group after the intervention when compared with the other two groups $(P=$ 0.02 ), but no significant difference was found between the two groups and the combined group (Table 6).

As shown in Table 7, no significant difference was determined between the three groups in terms of mean blood pressure, heart rate and arterial oxygen saturation $(p=0.6, p=0.4)$. Approximately, all groups showed similar hemodynamic parameters in the recovery room.

\section{Discussion}

Achieving an appropriate combination to increase the duration of analgesia in patients with chronic low back pain is one of the specific goals of anesthetics and pain

Table 2: Comparison of mean back pain duration before intervention in patients with chronic low back pain of the three groups

$\begin{array}{lllll}\text { Average back pain duration /group } & \text { Neostigmine group } & \text { Dexmedetomidine group } & \text { Combined group } & \text { P-value } \\ \text { Average back pain duration (Year) } & 1 / 8+/-0 / 85 & 1 / 65+/-0 / 56 & 1 / 78+/-0 / 68 & P=0.6 \\ & & & & \text { No significance }\end{array}$

Table 3: Comparison of patients' pain scores at different times after the intervention in patients with chronic low back pain of the three groups.

\begin{tabular}{|c|c|c|c|c|}
\hline Average pain/group & Neostigmine group & Dexmedetomidine group & Combined group & P-value \\
\hline $\begin{array}{l}\text { Pain score in the recovery } \\
\text { room }\end{array}$ & $0 / 38+/-0 / 22$ & $0 / 25+/-0 / 18$ & $0 / 21+/-0 / 16$ & $\begin{array}{l}P=0.4 \\
\text { No significant }\end{array}$ \\
\hline $\begin{array}{l}\text { Pain score } 1 \text { month after the } \\
\text { intervention }\end{array}$ & $7 / 9+/-6 / 7$ & $5 / 88+/-1 / 2$ & $5 / 42+/-1 / 1$ & $\begin{array}{l}P=0.02 \\
\text { Significant }\end{array}$ \\
\hline $\begin{array}{l}\text { Pain score } 3 \text { months after the } \\
\text { intervention }\end{array}$ & $7 / 1+/-1 / 1$ & $4 / 1+/-0 / 85$ & $4 / 1+/-0 / 64$ & $\begin{array}{l}P=0.01 \\
\text { Significant }\end{array}$ \\
\hline
\end{tabular}

Table 4: Comparison of the duration of post-injection analgesia in patients suffering from chronic low back pain of the three groups.
Analgesia/group
Neostigmine group
Dexmedetomidine group
Combined group
P-value
Duration of analgesia (days)
$14 / 8+/-2 / 9$
$16 / 1+/-2 / 3$
$16 / 7+/-2 / 7$
$P=0.03$
Significant

Table 5: Comparison of the mean time needed for movement onset after the intervention in patients with chronic low back pain of the three groups.

$\begin{array}{lcccc}\begin{array}{l}\text { Mean time needed for } \\ \text { movement onset/groups }\end{array} & \text { Neostigmine group } & \text { Dexmedetomidine group } & \text { Combined group } & \text { P-value } \\ \text { Movement onset (In hours) } & 2 / 87+/-0 / 65 & 2 / 61+/-0 / 98 & 2 / 4+/-0 / 66 & P=0.6 \\ & & & \text { No significance }\end{array}$

Table 6: Comparison of the ODI Score before and after the intervention in patients with chronic low back pain of the three groups.

\begin{tabular}{|c|c|c|c|c|}
\hline Group/score ODI & Neostigmine group & Dexmedetomidine group & Combined group & P-value \\
\hline $\begin{array}{l}\text { ODI Score before } \\
\text { intervention }\end{array}$ & $45.8 \%$ & $46.4 \%$ & $47.1 \%$ & $\begin{array}{l}P=0.6 \\
\text { No significant }\end{array}$ \\
\hline $\begin{array}{l}\text { ODI Score after } \\
\text { intervention }\end{array}$ & $42.4 \%$ & $38.7 \%$ & $38.1 \%$ & $\begin{array}{l}P=0.02 \\
\text { Significant }\end{array}$ \\
\hline
\end{tabular}


Table 7: Comparison of mean blood pressure, heart rate and arterial oxygen saturation in patients suffering from chronic low back pain in the recovery of the three groups.

$\begin{array}{lllll}\begin{array}{l}\text { Mean/group } \\ \text { MAP mean }\end{array} & \begin{array}{l}\text { Neostigmine group } \\ 88 / 2+/-1 / 1\end{array} & \begin{array}{l}\text { Dexmedetomidine group } \\ 87 / 6+/-3 / 4\end{array} & \begin{array}{l}\text { Combined group } \\ 86 / 6+/-2 / 7\end{array} & \begin{array}{l}\text { P-value } \\ P=0.4 \\ \text { No significance }\end{array} \\ \text { PR mean } & 82 / 6+/-3 / 1 & 81 / 8+/-3 / 7 & 82 / 2+/-2 / 9 & P=0.6 \\ \text { mean SPO2 } & 96.6 \% & & & \text { No significance } \\ & & 97.4 \% & 96.2 \% & P=0.6 \\ \end{array}$

management specialists. In our study, the comparison of the addition of dexmedetomidine and neostigmine to lidocaine $1.5 \%$ and triamcinolone for epidural block in patients suffering from chronic low back pain were studied. The results indicated that pain scores of patients of all three groups in the recovery room had dropped dramatically, but did not show any significant difference. However, pain scores were significantly different at one and three months after the intervention. Specifically, the pain scores in the dexmedetomidine group (D) and the combined group $(D+N)$ were significantly lower than the neostigmine $(\mathrm{N})$ group, but there were no differences between the dexmedetomidine and combined group).

The mean time needed for movement onset of patients was the same for all three groups, and analgesia duration was not significantly different among the three groups within 24 hours after the intervention. Comparison of the ODI scores in the three groups revealed that the scores were significantly reduced at one-month after the intervention in the dexmedetomidine and combined group compared to the neostigmine group. However, there was no significant difference between the dexmedetomidine and the combined group.

Our results are consistent with the previous studies. Nourmohammadpour et al. conducted a study in 2016 on 7889 Iranian patients aged 30-70 years with neck pain, back pain, and chronic knee pain. The prevalence rates of chronic neck pain, chronic low back pain, and chronic knee pain were $15.3 \%, 27.18 \%$ and $29.97 \%$, respectively. In the aforementioned study, in addition to identifying the risk factors for chronic low back pain and neck pain, the use of regional blocks has been recommended to reduce chronic pain in cases of chronic low back pain and neck pain. In our study, epidural block was capable of significantly reducing the pain of patients with chronic low back pain, which was consistent with the results of the above-mentioned study [19].

In another study conducted by Ackerma et al. in 2007, 90 patients aged 18-60 years with L5-S1 disc and chronic low back pain were evaluated. It has been determined that epidural injection using a caudal, intraluminal, and transforaminal approach have been effective in the chronic pain of the patients included in the study. Other results of the study mentioned above indicated that trans-foraminal epidural steroid injections were more effective compared to the caudal and intraluminal approach [6], results which were consistent with our study results as well because we also found that steroid injection by epidural block method leads to the reduction of pain in patients with chronic low back pain.

In another study, the effect of lumbar epidural block on patients with chronic low back pain has been investigated, where patients were divided into two groups: local anesthetic alone and local anesthetic in combination with betamethasone. The second group (combined group) showed a significant reduction in the ODI and pain scores compared to the first group (local anesthetic alone). The ODI score was found to be significantly reduced in $69 \%$ of patients of the first group and $83 \%$ of patients of the second group. Therefore, epidural injections of steroids together with local anesthetics have been shown to be effective in reducing chronic back pain [19].

These results were consistent with our findings; although all of the three local anesthetics and steroid anesthetics were administered epidurally in our study, the $\mathrm{ODI}$ and pain scores were reduced in our patients.

In 2015, Chou et al. discussed pain management injection therapies for patients suffering from low back pain, where epidural steroid injections for preventing the pain caused by chronic radiculopathies led to an immediate improvement in the function and reduced the pain of the patients.

However, the benefits of these injections were short and unstable and did not affect the need for long-term surgical care [20]. The epidural steroid injection, along with the local anesthetic, resulted in decreased pain and ODI scores (the result was consistent with ours), but a significant number of patients showed decreased pain scores three-months after the intervention, different from what Chou et al. stated.

Comparison of our study with prior research reports showed that our results were consistent with most of the previous studies. In our study, as in most previous studies, the injection of local and steroid anesthetics has led to a reduction in the chronic pain of the patients. 
Moreover, the addition of two adjuvants (neostigmine and dexmedetomidine) has led to a reduction in the pain and ODI scores. Regarding the use of both dexmedetomidine and neostigmine in the present study and their appropriate effects as an adjuvant along with local anesthetics and steroids, the final effect of these two adjuvants was compared to eventually provide an appropriate combination for increasing the duration of analgesia.

\section{Conclusions}

Afterepiduralblock, bothneostigmineanddexmedetomidine, along with local anesthetics and steroids, were capable of reducing the pain of patients suffering from chronic low back pain. Neostigmine has a lower effect on pain when compared to dexmedetomidine. Furthermore, the combination of the two drugs also reduced the pain scores of the patients after the intervention, although this reduction was not significant in comparison with the dexmedetomidine group.

\section{Acknowledgments}

We are grateful to the Clinical Research Center of Valiasr Hospital, the operative's operating room for Valiasr Hospital and the surgical team of Amir Al-Momenin Hospital.

\section{Conflict of Interest}

The authors confirm that there are no conflicts of interest.

\section{References}

1. Mohseni-Bandpei MA, Ahmad-Shirvani M, Golbabaei N, Behtash $H$, Shahinfar Z, Fernández-de-las-Peñas $C$. Prevalence and Risk Factors Associated with Low Back Pain in Iranian Surgeons. Journal of Manipulative \& Physiological Therapeutics. 2011;34(6):362-70.

2. Guha R, Bhattacharya D. Effect of transforaminal epidural block for relief of chronic low back pain with radiculopathy of multiple etiologies. Indian Journal of Pain. 2015;29:155.

3. Freburger JK, Holmes GM, Agans RP, et al. The rising prevalence of chronic low back pain. Archives of Internal Medicine. 2009;169(3):251-8.

4. Iannuccilli JD, Prince EA, Soares GM. Interventional Spine Procedures for Management of Chronic Low Back Pain—A Primer. Seminars in Interventional Radiology. 2013;30(3):307-17.

5. Manchikanti L, Singh V, Cash KA, Pampati V, Damron KS, Boswell MV. Effect of fluoroscopically guided caudal epidural steroid or local anesthetic injections in the treatment of lumbar disc herniation and radiculitis: a randomized, controlled, double blind trial with a twoyear follow-up. Pain physician. 2012;15(4):273-86.

6. Ackerman WE, 3rd, Ahmad M. The efficacy of lumbar epidural steroid injections in patients with lumbar disc herniations. Anesthesia and analgesia. 2007;104(5):1217-22.

7. Manchikanti L, Singh V, Cash KA, Pampati V, Damron KS, Boswell MV. A randomized, controlled, double-blind trial of fluoroscopic caudal epidural injections in the treatment of lumbar disc herniation and radiculitis. Spine. 2011;36(23):1897-905.

8. Manchikanti L, Cash KA, McManus CD, Pampati V, Fellows B. Fluoroscopic caudal epidural injections with or without steroids in managing pain of lumbar spinal stenosis: one-year results of randomized, double-blind, active-controlled trial. Journal of spinal disorders \& techniques. 2012;25(4):226-34.

9. Amr YM. Effect of addition of epidural ketamine to steroid in lumbar radiculitis: one-year follow-up. Pain physician. 2011;14(5):475-81.

10. McLain RF, Kapural L, Mekhail NA. Epidural steroid therapy for back and leg pain: mechanisms of action and efficacy. The Spine Journal. 2005;5(2):191-201.

11. Stafford MA, Peng P, Hill DA. Sciatica: a review of history, epidemiology, pathogenesis, and the role of epidural steroid injection in management. British Journal of Anaesthesia. 2007;99(4):461-73.

12. Imani $f$, zafarghandi motlagh $m$, khaleghipour $m$, noghrekar a, alebouyeh $\mathrm{m}$, entezari s. Transforaminal epidural block with dexmedetomidine vs. corticosteroid in patients with chronic radicular low back pain. Anesthesiology and Pain. 2015;5(2):1-13.

13. Kamali A, Moshiri E, Zareei A. A comparison between neostigmine and ketamine as adjuvant with bupivacaine $0.25 \%$ in epidural methof for post-operative pain control in patients with femoral fracture and candidate for elective surgery (Medical residency dissertation). Retrieved from Department of Anesthesiology, Faculty of Mdecine, Arak University of Medical Sciences 2014.

14. Sharma A, Kumar NJ, Azharuddin M, Mohan LC, Ramachandran G. Evaluation of low-dose dexmedetomidine and neostigmine with bupivacaine for postoperative analgesia in orthopedic surgeries: A prospective randomized double-blind study. Journal of Anaesthesiology Clinical Pharmacology. 2016;32(2):187-91.

15. Kida K, Ohtani N, Shoji K, Yasui Y, Masaki E. Postoperative pain status after intraoperative systemic dexmedetomidine and epidural neostigmine in patients undergoing lower abdominal surgery. Eurpoean Journal of Anesthseiology 2008;25(11):869-75.

16. Qiao Sheng Z, Sheng Jin G, Bei W, Zhang Gang X. Optimal singledose epidural neostigmine for postoperative analgesia after partial hepatectomy. Indian Journal of Pharmacology. 2014;46(6):613-6.

17. Helal S, Eskandr A, Gaballah K, Gaarour I. Effects of perineural administration of dexmedetomidine in combination with bupivacaine in a femoral-sciatic nerve block. Saudi Journal of Anaesthesia. 2016;10(1):18-24.

18. Noormohammadpour P, Mansournia MA, Koohpayehzadeh J, Asgari F, Rostami M, Rafei A, et al. Prevalence of Chronic Neck Pain, Low Back Pain and Knee Pain and their Related Factors in Community-dwelling Adults in Iran: A Population-based National Study. Clin J Pain. 2017 Feb;33(2):181-187.

19. Manchikanti L, Singh V, Falco FJ, Cash KA, Pampati V. Evaluation of the effectiveness of lumbar interlaminar epidural injections in managing chronic pain of lumbar disc herniation or radiculitis: a randomized, double-blind, controlled trial. Pain physician. 2010;13(4):343-55.

20. Chou R, Hashimoto R, Friedly J, Fu R, Dana T, Sullivan S, et al. AHRQ Technology Assessments. Pain Management Injection Therapies for Low Back Pain. Rockville (MD): Agency for Healthcare Research and Quality (US); 2015. PMID: 25879124. 